\title{
Structural Characterization and Differentiation of Modified Isomeric Tryptophans
}

\author{
Gianluca Giorgi, Laura Salvini, and Fabio Ponticelli \\ Centro Interdipartimentale di Analisi e Determinazioni Strutturali, and Dipartimento di Chimica, Università di \\ Siena, Siena, Italy
}

\begin{abstract}
Different mass spectrometry (MS) techniques have been applied to the study of modified tryptophan isomers obtained by photochemical reactions. The gas phase behavior of the molecular ions and the most abundant fragment ions produced under electron ionization has been selectively studied by MS/MS experiments. Both the fragmentation reactions occurring in the ion source, as well as those produced under collision-induced dissociation conditions have allowed to characterize and differentiate each isomer from the others. Investigation of a bisubstituted derivative has been useful in the rationalization of the gas phase behavior of this series of modified tryptophans. This study has allowed the evaluation of the role played by the substituents and their positions at the indolic ring on the gas phase decompositions that are distinctive and selective for each isomer. The occurrence of regiospecific reactions suggests that isomerization phenomena do not occur either in the molecular ions or in the main fragment ions in the gas phase. (J Am Soc Mass Spectrom 2002, 13, 1298-1303) (C) 2002 American Society for Mass Spectrometry
\end{abstract}

$\mathrm{T}$ here is a growing interest in synthesizing modified amino acids and in the creation of unnatural amino acid combinatorial libraries. With modified compounds it is possible to obtain new inhibitors of enzymes [1], information about the importance of some structural elements, and assess the role of residues in catalytic/substrate binding, enzyme structure, and thermal stability of the molecule. Modified amino acids can be also useful markers for specific sites inside the structures of peptides and proteins thus representing an important tool for their structural characterization. Tryptophan residues are essential for the activity of various endogenous peptides [2,3], and their modification can completely alter the activity of the enzymes $[4,5]$.

The availability of methods that allow an unambiguous characterization and differentiation of modified amino acid derivatives is very important. As most of them are isomers, high specificity and selectivity, together with good sensitivity, are required. Mass spectrometry is an important tool that can be conveniently used for the characterization of isomeric ion structures. In particular, it has been used in studying the indole skeleton that characterizes tryptophan [6-12].

In the frame of a research project aimed at the gas phase characterization and differentiation of heterocyclic isomers [13-16], we wish to report here on a study

Published online September 25, 2002

Address reprint requests to Dr. G. Giorgi, Centro Interdipartimentale di Analisi e Determinazioni Strutturali, and Dipartimento di Chimica, Università di Siena, via Aldo Moro, 53100 Siena, Italy. E-mail: gianluca.giorgi@unisi.it of the modified tryptophans 1-4 (Scheme 1) obtained by photochemical reactions [17]. As these compounds are potentially useful in the chemistry of peptides and proteins, their characterization and differentiation are particularly interesting.

Compounds 1-3 are positional isomers, differing for the position of the $\alpha$-cyanoethyl substituent at the indolic ring. The behavior of high internal energy ions formed in the source has been investigated by low and high resolution MS. MS/MS experiments have been carried out on both the molecular and the most abundant fragment ions. The comparison with the bisubstituted derivative 4 has allowed the evaluation of the influence of the position of the $\alpha$-cyanoethyl substituent on the decomposition pathways.

\section{Experimental}

Compounds 1-4 were synthesized by photochemical irradiation of $\mathrm{N}$-acetyltryptophan methyl ester in the presence of an excess of acrylonitrile, as previously reported [17]. Mass spectrometric measurements were performed on a VG 70-250S two sector mass spectrometer (VG Analytical Ltd., Manchester, UK) connected to an OPUS 2000 data system. Electron ionization was performed at $70 \mathrm{eV}$, emission current $0.2 \mathrm{~mA}$, with a source temperature of $200{ }^{\circ} \mathrm{C}$. The accelerating voltage was $8 \mathrm{kV}$ and the resolution was $1000 \mathrm{M} / \Delta \mathrm{M}(10 \%$ valley), or $10,000 \mathrm{M} / \Delta \mathrm{M}(10 \%$ valley) under high resolution conditions.

The samples were introduced in the EI source via the direct inlet without heating the probe. Appropriate 
<smiles>[R]c1cc([R6])c2c(CC(NC(C)=O)C(C)=O)cn([Z1])c2c1</smiles>

1. $\mathrm{R}_{1}=\mathrm{CH}(\mathrm{CN}) \mathrm{CH}_{3}$

2. $\mathrm{R}_{1}=\mathrm{R}_{3}=\mathrm{H}$

3. $\mathrm{R}_{1}=\mathrm{R}_{2}=\mathrm{H}$

4. $\mathrm{R}_{1}=\mathrm{R}_{3}=\mathrm{CH}(\mathrm{CN}) \mathrm{CH}_{3} \quad \mathrm{R}_{2}=\mathrm{H}$

Scheme 1

linked scans between the electrostatic and the magnet sectors were used to detect parent and product ions, and decompositions involving neutral losses. Collisioninduced dissociation (CID) experiments were carried out by introducing argon in the collision cell located in the first field free region until the intensity of the main beam was reduced to $50 \%$ of its original value. Replicated measurements showed that the reproducibility of the relative peak abundances in CID spectra was within $10 \%$.

\section{Results and Discussion}

\section{Mass Spectra}

Unlike from positional isomers that often produce similar mass spectra [13], the compounds under investigation give rise to fragmentation reactions in the ion source that result in being distinctive and specific depending on the position of the $\alpha$-cyanoethyl substituent at the indolic ring (Figure 1). Most of the unimolecular reactions are the same for all the isomers, but there are great differences in the relative abundances of the product ions.

For Compounds 1-3, the molecular ions are not very abundant (6 (3) $\div 22 \%$ (2)). The base peak is at $\mathrm{m} / \mathrm{z} 183$ and corresponds to the elimination of the $\mathrm{CH}\left(\mathrm{COOCH}_{3}\right) \mathrm{NHCOCH}_{3}$ radical from the molecular ion. Similar to analogous derivatives [18, 19], the high stability of the species at $\mathrm{m} / \mathrm{z} 183$ can be reasonably attributed to an expansion of the five membered ring yielding a very stable $\alpha$-cyanoethylquinolinium ion (Scheme 2).

Another common unimolecular process followed by isomers 1-3 yields fragment ions at $\mathrm{m} / \mathrm{z} 254$. They might be produced by loss of the $\mathrm{COOCH}_{3}$ radical or by that

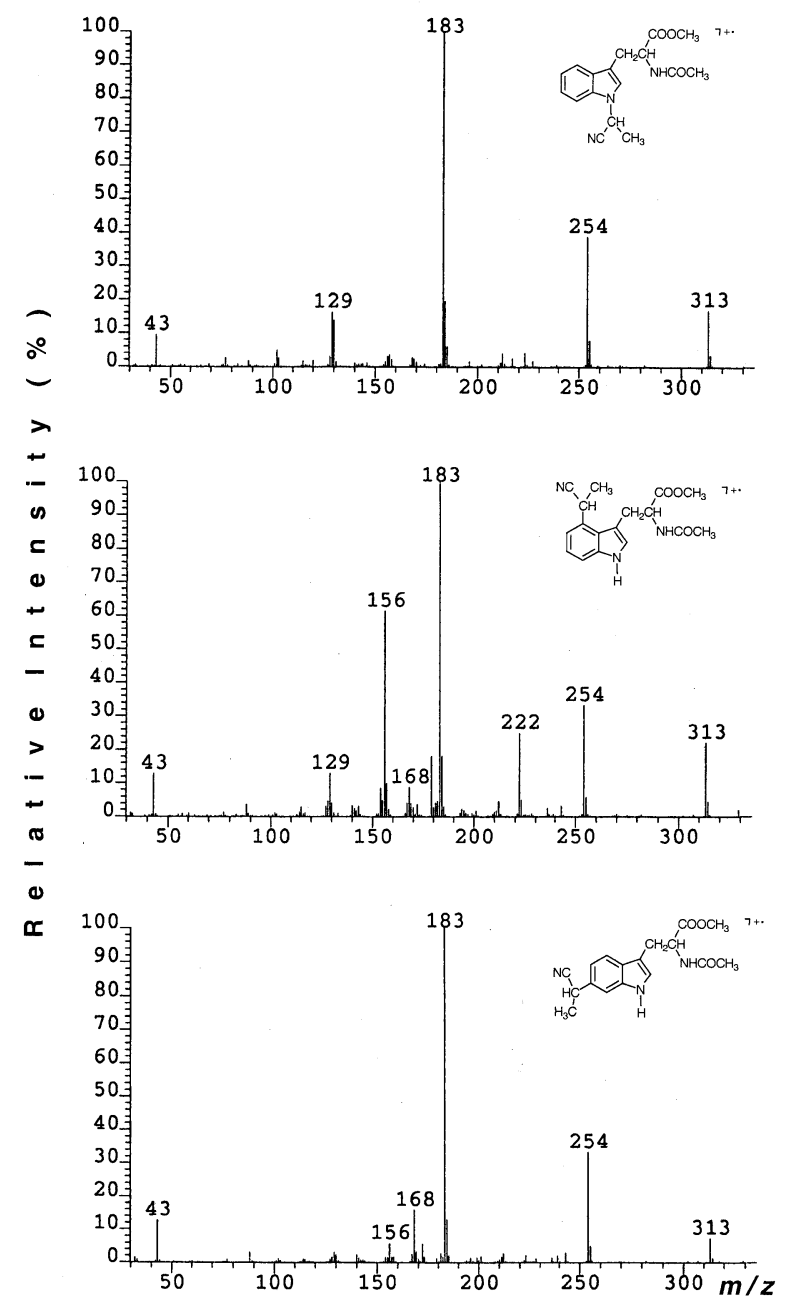

Figure 1. Electron ionization $(70 \mathrm{eV})$ mass spectra of derivatives 1 (top), 2 (middle), and 3 (bottom).

of $\mathrm{NH}_{2} \mathrm{COCH}_{3}$ from the molecular ions. Accurate mass measurements have allowed the determination that the elimination of $\mathrm{NH}_{2} \mathrm{COCH}_{3}$ occurs. This reaction involves the rearrangement of one hydrogen on the leaving group, reasonably from the adjacent methylene group.

The position of the substituent yields specific and distinctive fragmentation reactions. The spatial proximity between the substituent at position 3 of the indolic ring and the $\alpha$-cyanoethyl group causes a distinctive loss of methanol from ions at $\mathrm{m} / \mathrm{z} 254$ of derivative 2 (Figure 1, middle), yielding fragment ions at $\mathrm{m} / \mathrm{z} 222$. These ions can further lose a $\mathrm{CH}_{3} \mathrm{CO}$ radical producing cations at $\mathrm{m} / \mathrm{z} 179$, that are distinctive for isomer 2 (Figure 1, middle).

Isomers 1-3 show other common fragmentation pathways with large differences in relative abundances of the product ions. One of these consists of the loss of HCN from the species at $m / z 183$, thus producing ions at $\mathrm{m} / \mathrm{z} 156$, whose abundance is very scarce for isomers 1 and $3(<5 \%)$ but high for compound $2(64 \%)$ (Figure 1, Scheme 2). Also ions at $\mathrm{m} / \mathrm{z} 168$, whose elemental 


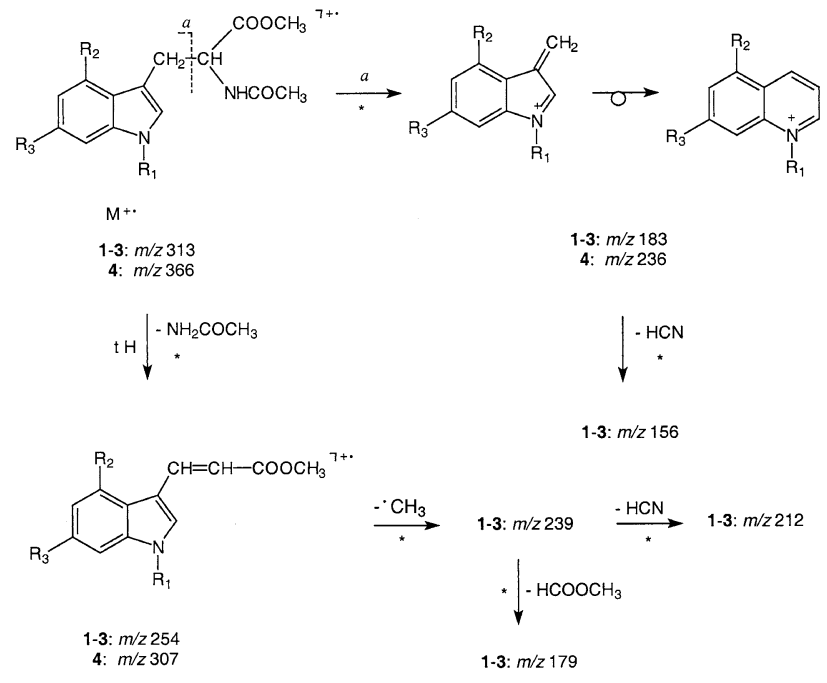

* also occurring under CID conditions

Scheme 2

composition corresponds to $\left[\mathrm{C}_{11} \mathrm{H}_{8} \mathrm{~N}_{2}\right]^{+\cdot}$, show differences in their relative abundances in the mass spectra of the three isomers, being more abundant for compounds 2 and 3 (Figure 1).

Another important isomeric differentiation concerns the ions at $\mathrm{m} / \mathrm{z} 129$ and 130 that formally correspond to a quinolyl radical cation and a quinolinium ion, respectively. Ions at $\mathrm{m} / \mathrm{z} 129$ show close abundances for $\mathbf{1}$ $(16 \%)$ and $2(12 \%)$, while for isomer 3 they are very scarce. On the other hand, the formation of quinolinium ions $(\mathrm{m} / \mathrm{z} 130)$ occurs in a large extent only for $\mathbf{1}$, thus allowing a further differentiation from isomers $\mathbf{2}$ and $\mathbf{3}$ (Figure 1).

The insertion of a second $\alpha$-cyanoethyl substituent at the indolic ring, as it occurs in derivative 4, does not produce big changes in the fragmentation reactions occurring in the ion source (Figure 2, top). The molecular ion $(\mathrm{m} / \mathrm{z} 366)$ has a relative abundance $(20 \%)$ close to those observed for isomers 1-3. Similarly, the base peak is produced by fragmentation of the substituent at position 3 of the indolic ring and it corresponds to the elimination of the $\mathrm{CH}\left(\mathrm{COOCH}_{3}\right) \mathrm{NHCOCH}_{3}$ radical from the molecular ion, yielding species at $\mathrm{m} / \mathrm{z} 236$. The latter can further decompose by loss of $\mathrm{CH}_{2} \mathrm{CHCN}$ giving product ions at $\mathrm{m} / \mathrm{z} 183$. Alternatively, the molecular ion of 4 can eliminate $\mathrm{NH}_{2} \mathrm{COCH}_{3}$ as confirmed by accurate mass measurements of ions at $\mathrm{m} / \mathrm{z} 307$, followed by loss of HCN, thus producing ions at $\mathrm{m} / \mathrm{z} 280$.

\section{Collision-Induced Dissociations}

Molecular ions. The CID product ion mass spectra obtained by selecting the molecular ion of isomers 1-3 as the main beam show two kinds of reactions: common decomposition pathways that yield the most abundant ions and regiochemical reactions whose occurrence is

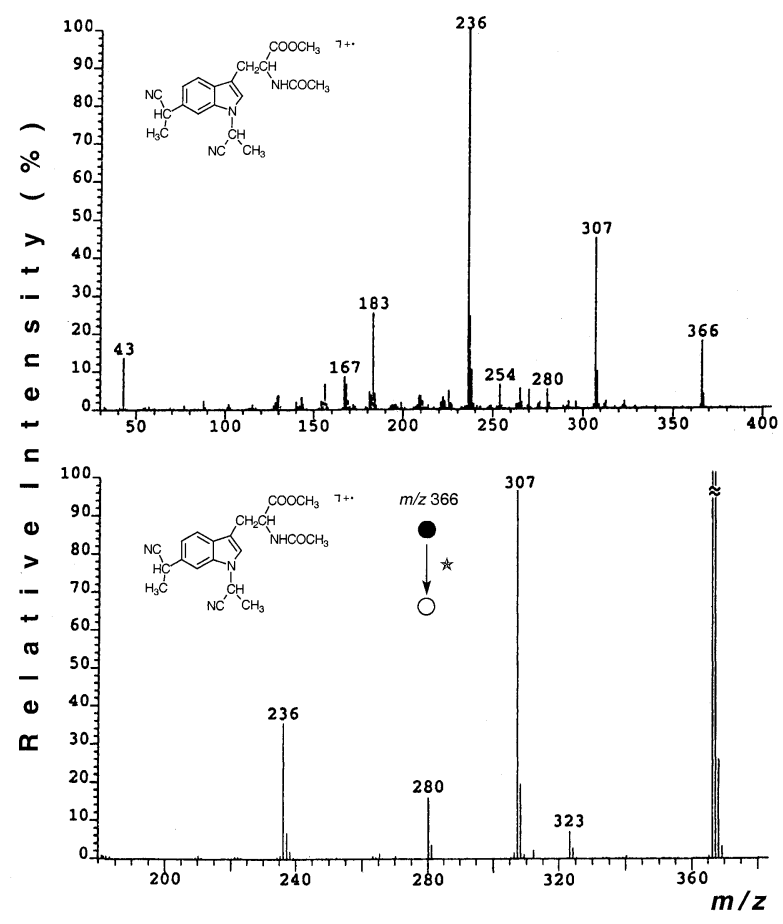

Figure 2. Gas phase characterization of Compound 4: Mass spectrum (EI, $70 \mathrm{eV}$ ) (top), and CID product ion spectrum of its molecular ion $(\mathrm{m} / \mathrm{z} 366)$ (bottom).

depending on the position of the $\alpha$-cyanoethyl group at the indolic ring.

For the three isomers, the most abundant ions are at $\mathrm{m} / \mathrm{z} 254$ and 183, suggesting behavior similar to that shown by high internal energy ions inside the source (Scheme 2). The isomeric differentiation is highly evident and specific by considering minor ionic species present in the CID spectra. As an example, ions at $\mathrm{m} / \mathrm{z}$ 227 that are specific for isomer 1 originate from ions at $\mathrm{m} / \mathrm{z} 254$ by loss of $\mathrm{HCN}$. Ions at $\mathrm{m} / \mathrm{z} 129$, which formally correspond to a quinolyl radical cation, are produced distinctively by the same isomer.

In addition to the different relative intensity of ions at $m / z 183$, isomer 2 can also be distinguished from the two others by the presence of ions at $\mathrm{m} / \mathrm{z} 222$ and 170 . The former are produced by loss of methanol from the species at $\mathrm{m} / \mathrm{z} 254$. The loss of methanol ions at $\mathrm{m} / \mathrm{z} 254$ is favored by isomer 2 because there is spatial proximity between the two substituents at positions 3 and 4 of the indolic ring (see below). Ions at $\mathrm{m} / \mathrm{z} 170$ formally correspond to 4-(1-cyanoethyl)indole and might be formed by loss of the substituent at position 3 from $\mathrm{M}^{+}$. with hydrogen rearrangement. Derivative 3 can be easily differentiated from the other isomers by the absence of ions at $m / z 227,222$, and 170 , while ions at $\mathrm{m} / \mathrm{z} 183$ have the lesser abundance. Ions at $\mathrm{m} / \mathrm{z} 168$ are also present in the CID mass spectrum of 3 . The CID product ion mass spectrum of derivative 4 (Figure 2, bottom) shows the most abundant ions at $\mathrm{m} / \mathrm{z} 307$ that correspond to the loss of $\mathrm{NH}_{2} \mathrm{COCH}_{3}$ from the molecular ion. Similarly to what occurs for isomer 1, a 
prominent loss of $\mathrm{HCN}$ is observed from this species producing ions at $m / z 280$. It follows that the detection of this reaction pathway is highly specific and diagnostic for the presence of the $\alpha$-cyanoethyl substituent at the endocyclic nitrogen.

Ions at $m / z 236$ are analogous to those at $m / z 183$ produced by isomers 1-3 and correspond to the elimination of ${ }^{\circ} \mathrm{CH}\left(\mathrm{COOCH}_{3}\right) \mathrm{NHCOCH}_{3}$ from the molecular ion. Their relative abundance $(36 \%)$ is close to that observed for the ions at $m / z 183$ produced by $\mathbf{1}$. Unlike from isomers 1-3, ions $[\mathrm{M}-43]^{+}$, attributable to the loss of the $\mathrm{COCH}_{3}$ radical, are observed for 4 .

[M $\left.-\mathrm{NH}_{2} \mathrm{COCH}_{3}\right]^{+\cdot}$ fragment ions. The study of the CID mass spectra produced by fragment ions allows a better insight into the structural characterization and isomeric differentiation of compounds 1-4. Furthermore, it is useful to establish whether isomerization phenomena occur after partial decomposition of the molecular ion.

By analyzing the CID product ion mass spectra obtained by selecting the species $\left[\mathrm{M}-\mathrm{NH}_{2} \mathrm{COCH}_{3}\right]^{+}$. $(\mathrm{m} / \mathrm{z} 254)$ formed in the ion source by isomers $\mathbf{1}-\mathbf{3}$ two main decomposition pathways can be envisaged: one begins from the fragmentation of the substituent at position 3, the other involves the decomposition of the $\alpha$-cyanoethyl group (Figure 3). A spectacular regiochemical effect is observed with regard to the most abundant ions produced under the CID regime: while for isomers 1 and 3 they are at $m / z 223$, for compound 2 they are at $m / z 222$ (Figure 3). In the former case a methoxy radical is lost, while elimination of methanol occurs distinctively from 2 . The latter can be rationalized by considering the spatial proximity effect between the substituents at positions 3 and 4 of the indolic ring in the structure of 2 . This should allow a hydrogen transfer from the methine of the $\alpha$-cyanoethyl group to the methoxyl thus allowing elimination of $\mathrm{CH}_{3} \mathrm{OH}$.

Owing to the loss of $\mathrm{OCH}_{3}$ from ions at $\mathrm{m} / \mathrm{z} 254$ of isomers 1 and 3, a new fused five membered ring can reasonably be formed, thus producing very stable tricyclic cations at $m / z 223$. The latter further decompose by loss of HCN yielding ions at $m / z$ 196, whose relative intensities are similar for the two isomers. The radical ions at $m / z 222$ yielded by 2 do not lose HCN.

Another decomposition pathway followed by the species $\left[\mathrm{M}-\mathrm{NH}_{2} \mathrm{COCH}_{3}\right]^{+\cdot}$ involves the loss of a methyl radical and produces cations at $\mathrm{m} / \mathrm{z} 239$ whose relative intensity increases passing from $2(4 \%)$ to 1 $(18 \%)$ and 3 (93\%) (Figure 3). The large difference in the relative intensities of the product ions suggests that the loss of $\mathrm{CH}_{3}$ occurs from the $\alpha$-cyanoethyl substituent whose position is distinctive for each isomer. Owing to this, it is reasonable to say that the pendant $\mathrm{C}_{2} \mathrm{HN}$ chain gives rise to a new pyrrole ring fused at different edges of the indolic ring, depending on the position of the substitution. Also, the CID mass spectrum of the ions $\left[\mathrm{M}-\mathrm{NH}_{2} \mathrm{COCH}_{3}\right]^{+\cdot}$ produced by the 1,6-bisubstituted compound 4 shows the loss of ${ }^{\circ} \mathrm{CH}_{3}$ and that of ${ }^{\circ} \mathrm{OCH}_{3}$.

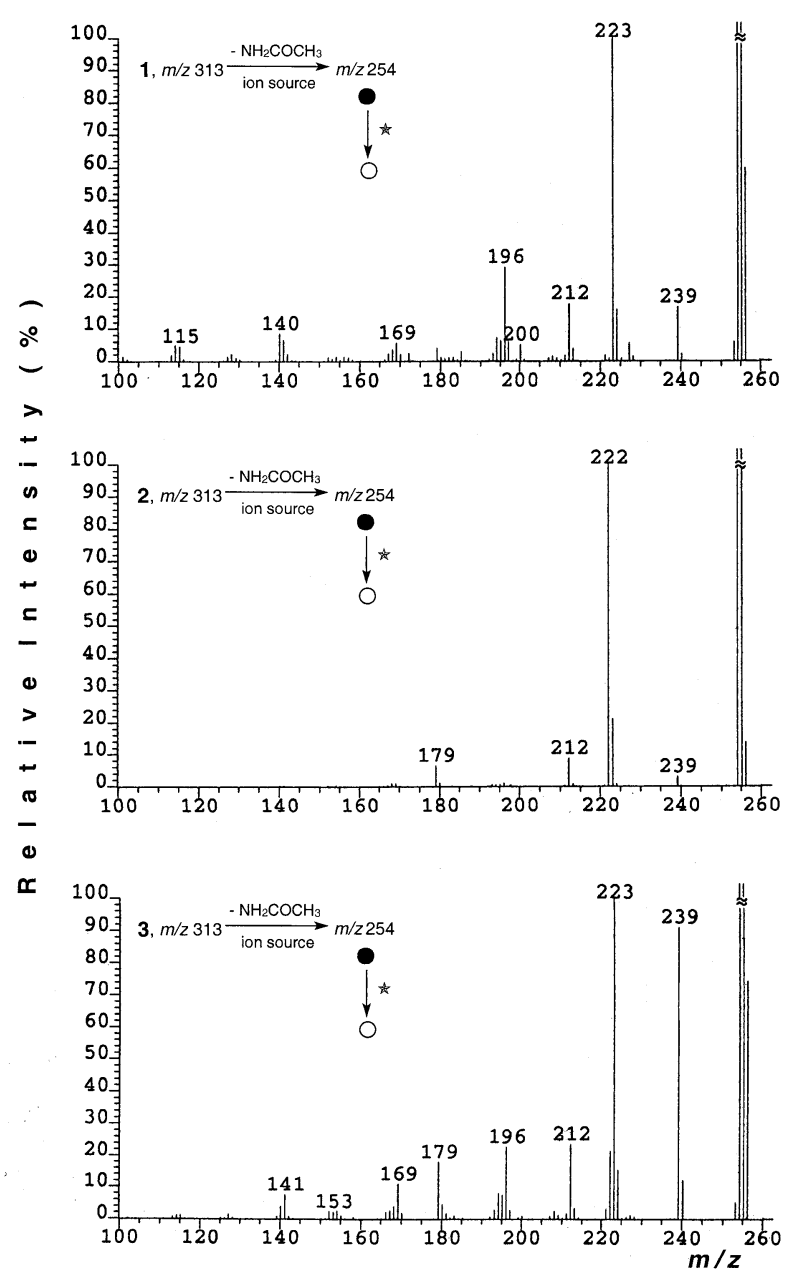

Figure 3. CID product ion spectra obtained by selecting the [M $\left.\mathrm{NH}_{2} \mathrm{COCH}_{3}\right]^{+\cdot}$ fragment ions $(\mathrm{m} / \mathrm{z} 254)$ from isomers 1 (top), 2 (middle), and 3 (bottom).

As this behavior is similar to that shown by compound 3 , it is reasonable to say that the loss of the methyl radical occurs from the substituent at position 6 .

An additional factor that might contribute to the high intensities of the species $\left[\left(\mathrm{M}-\mathrm{NH}_{2} \mathrm{COCH}_{3}\right)-\right.$ $\left.\mathrm{CH}_{3}\right]^{+}$observed for 3 and 4 might be ascribed to the competition between the two decomposition reactions that involve the loss of ${ }^{\circ} \mathrm{OCH}_{3}$ and ${ }^{\circ} \mathrm{CH}_{3}$. This competition, absent in the case of $\mathbf{2}$ and relatively scarce for $\mathbf{1}$, strongly differentiates isomer $\mathbf{3}$ and compound $\mathbf{4}$ from the other two regioisomers. Ions at $\mathrm{m} / \mathrm{z} 239$ produced by 1-3 can decompose by loss of HCN or by elimination of methylformiate yielding cations at $m / z 212$ and 179, respectively. The large differences in their relative intensities still allow isomeric differentiation of the three compounds. Analogous pathways are also observed for 4 and produce ions at $m / z 265$ and 232, respectively.

Another common decomposition concerns the elimination of the whole substituent at position 3 of the indolic ring. This causes the formation of ions at $m / z 169$ that are much more intense for $\mathbf{3}$ and $\mathbf{1}$ than for $\mathbf{2}$ (Figure 3). An analogous pathway occurs also for 4 and 
yields ions at $m / z 222$. These can further fragment by loss of a methyl radical thus producing cations at $\mathrm{m} / \mathrm{z}$ 207. Unlike from 2 and 3 , the $\left[\mathrm{M}-\mathrm{NH}_{2} \mathrm{COCH}_{3}\right]^{+\cdot}$ ions produced by isomer $\mathbf{1}$ give rise to other decomposition reactions that yield not very intense but highly distinctive ionic species, such as the loss of $\mathrm{HCN}$ and the elimination of the $\alpha$-cyanoethyl group bound to $\mathrm{N}(1)$.

$\left[\mathrm{M}-\mathrm{CH}\left(\mathrm{COOCH}_{3}\right) \mathrm{NHCOCH}_{3}\right]^{+}$fragment ions. Owing to the elimination of the $\mathrm{CH}\left(\mathrm{COOCH}_{3}\right) \mathrm{NHCOCH}_{3}$ radical from the molecular ions of isomers $1-3$, it is reasonable to say that a rearrangement yielding a ring expansion of the pyrrole ring occurs in the gas phase [19]. The resulting substituted quinolinium cations $(\mathrm{m} / \mathrm{z}$ 183, Scheme 2) show decompositions that are strongly influenced by the position of the $\alpha$-cyanoethyl group. Ions at $m / z 183$ generally follow the same CID pathways but great differences in product ion intensities are observed, thus evidencing specific and distinctive gas phase behavior (Figure 4).

For isomer 1, in which the substituent is bound to the indolic nitrogen, a quite extended decomposition pattern is observed (Figure 4, top). The most intense product ions are at $m / z 129(100 \%)$ and $130(73 \%)$ due to the elimination of the $\alpha$-cyanoethyl radical and $\mathrm{C}_{3} \mathrm{H}_{3} \mathrm{~N}$, respectively. These abundant decompositions, detectable only at trace level for the other two isomers, are diagnostic for the presence of the $\alpha$-cyanoethyl group at the indolic nitrogen. Ions at $\mathrm{m} / \mathrm{z} 129$ can further eliminate $\mathrm{HCN}$, a typical fragmentation of quinoline, thus producing the species at $\mathrm{m} / \mathrm{z} 102$ (Figure 4, top). Although quinolinium cations formed by isomers 2 and 3 have the $\alpha$-cyanoethyl substituent at the benzene ring, they follow regiospecific decomposition reactions that allow their unambiguous characterization and differentiation in the gas phase. In the case of $\mathbf{2}$, ions at $m / z 156$, due to elimination of $\mathrm{HCN}$, carry most of the total ion current (Figure 4, middle). The same loss is also observed for isomers $\mathbf{1}$ and 3, reasonably from the $\alpha$-cyanoethyl substituent. On the other hand, for compound 3 the most important decomposition reaction corresponds to the loss of a methyl radical (Figure 4, bottom).

Product ions at $m / z 140$ are also produced in small amount by isomers 1-3, and correspond to consecutive eliminations of ${ }^{\circ} \mathrm{CH}_{3}$ and ${ }^{\circ} \mathrm{CH}_{2} \mathrm{~N}$ from ions at $\mathrm{m} / \mathrm{z} 183$. The loss of the $\mathrm{CH}\left(\mathrm{COOCH}_{3}\right) \mathrm{NHCOCH}_{3}$ radical from the molecular ion of derivative 4 produces ions at $\mathrm{m} / \mathrm{z}$ 236. As expected, most of the CID decompositions resembles those produced by isomers $\mathbf{1}$ and 3 . The losses of ${ }^{\circ} \mathrm{CH}_{3}$ and $\mathrm{HCN}$ yield intense ions at $\mathrm{m} / \mathrm{z} 221$ and 209, respectively, while the most abundant product ions are at $m / z$ 183. They are produced by elimination of $\mathrm{C}_{3} \mathrm{H}_{3} \mathrm{~N}$, most probably from the position 1 of the indolic ring; formally they correspond to a monosubstituted $\alpha$-cyanoethyl quinolinium ion. This latter can eliminate a methyl radical or $\mathrm{HCN}$ producing ions at $m / z 168$ and 156 , respectively. Alternatively, a ${ }^{\circ}{ }_{3} \mathrm{H}_{4} \mathrm{~N}$ radical can be lost from the species at $\mathrm{m} / \mathrm{z} 236$. The resulting ions $(\mathrm{m} / \mathrm{z}$

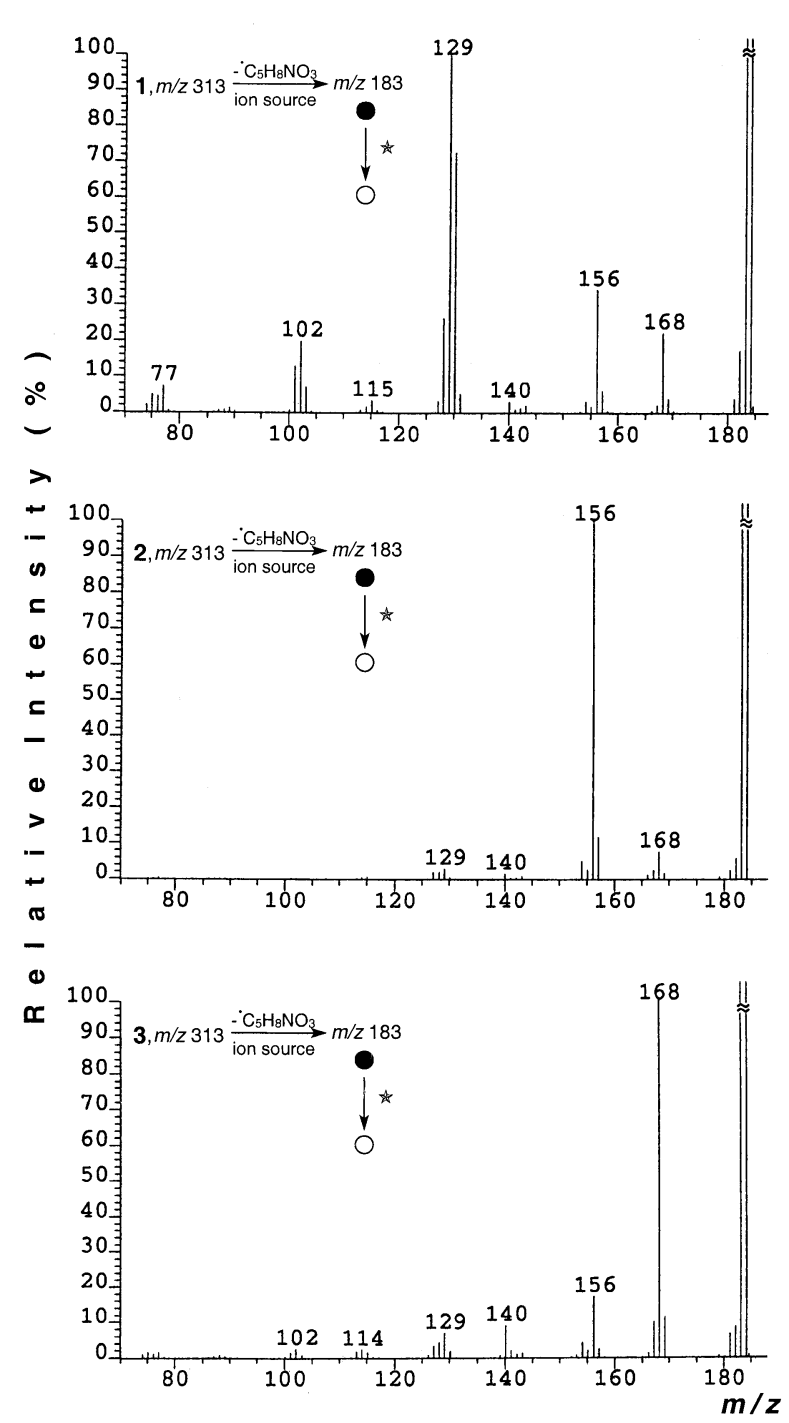

Figure 4. CID product ion spectra obtained by selecting the [M $\left.\mathrm{CH}\left(\mathrm{COOCH}_{3}\right) \mathrm{NHCOCH}_{3}\right]^{+}$fragment ions $(\mathrm{m} / z$ 183) from isomers 1 (top), 2 (middle), and 3 (bottom).

182) can lose a methyl radical yielding abundant ions at $\mathrm{m} / \mathrm{z} 167$.

\section{Conclusion}

The present study has shown that different mass spectrometry and MS/MS techniques are useful tools for the structural characterization and differentiation of modified tryptophan isomers. These compounds can be potentially useful in the creation of unnatural amino acid libraries and in the synthesis of modified peptides.

The study of the mass spectra of isomers 1-3 and derivative 4 has evidenced specific and distinctive fragmentation reactions that occur in the ion source depending on the position of the substituents at the indolic ring. The investigation has been extended to the study of CID reactions followed by the molecular ions and the most intense fragment ions produced in the source. This has allowed to increase specificity and 
selectivity and to obtain useful information on gas phase ion structures. Also, under the CID regime regiospecific decompositions occur, depending on the position of the $\alpha$-cyanoethyl moiety at the indolic ring.

The results have shown that each compound maintains its own distinctive structure, not only after one electron removal like it occurs under electron ionization, but also after partial decomposition of its substituents at the indolic ring. The detection of regiospecific reactions that characterize each ionic species has allowed to exclude the occurrence of isomerization phenomena in the gas phase.

\section{References}

1. Lescrinier, T.; Busson, R.; Rozenski, J.; Janssen, G.; Van Aerschot, A.; Herdewijn, P. Incorporation of 5-Hydroxytryptophan in Oligopeptides. Tetrahedron 1996, 52, 6965-6972.

2. MacLeod, A. M.; Merchant, K. J.; Brookfield, F.; Kellcher, F.; Stevenson, G.; Owens, A. P.; Swain, C. J.; Cascieri, M. A.; Sadowski, S.; Ber, E.; Shader, C. D. Mac; Intyre, D. E.; Metzger, J. M.; Ball, M. G.; Baker, R. Identification of L-Tryptophan Derivatives with Potent and Selective Antagonist Activity at NK1 Receptor. J. Med. Chem. 1994, 37, 1269-1274.

3. Shibata, D.; Steczko, J.; Dixon, J. E.; Hermodson, H.; Yazdanparast, R.; Axelrod, B. Primary Structure of Soybean Lipoxygenase-1. J. Biol. Chem. 1987, 262, 10080-10085.

4. Klein, B. P.; Cohen, B. S.; Grossman, S.; King, D.; Malovany, H.; Pinsky, A. Effect of Modification of Soybean Lipoxygenase-1 With N-Bromosuccinimide on Linoleate Oxidation, Pigment Bleaching and Carbonyl Production. Phytochemistry 1985, 24, 1903-1906.

5. Srinivasulu, S.; Rao, A. G. A. Role of Tryptophan Residues of Lipoxygenase-1 in Activity, Structure, and Stability: Chemical Modification Studies with N-Bromosuccinimide. Food Chem. 2000, 70, 199-204.

6. Powers, J. C. The Mass Spectrometry of Simple Indoles. J. Org. Chem. 1968, 33, 2044-2050.

7. Marx, M.; Djerassi, C. Mass Spectrometry in Structural and Stereochemical Problems. CXLIX. The Question of Ring Ex- pansion in the Fragmentation of ${ }^{13} \mathrm{C}$-Labeled Nitrogen Heterocycles. J. Am. Chem. Soc. 1968, 90, 678-681.

8. Corval, M. Elimination sous Impact Electronique de HCN et $\mathrm{H}^{-}$a partir de l'Indole. Comparaison avec l'Indolizine. Org. Mass Spectrom. 1979, 14, 213-219.

9. Corval, M. An Electron Impact Study of HCN Elimination from Indole by Use of ${ }^{13} \mathrm{C}$ Labeling. Org. Mass Spectrom. 1981, 16, 444-447.

10. Rodriguez, J. G.; Canoira, L. Electron Impact Mass Spectrometry of Indoline Derivatives. Int. J. Mass Spectrom. Ion Processes 1995, 142, 23-29.

11. Rodriguez, J. G.; Urrutia, A.; Canoira, L. Electron Impact Mass Spectrometry of Indole Derivatives. Int. J. Mass Spectrom. Ion Processes 1996, 152, 97-110.

12. Porter, Q. N. Mass Spectrometry of Heterocyclic Compounds. J. Wiley and Sons: New York, 1985; 2nd ed.; pp 555-580 and references therein.

13. Giorgi, G.; Ponticelli, F.; Czira, G.; Vékey, K. Characterization and Differentiation of Heterocyclic Isomers. Tandem Mass Spectrometry and Molecular Orbital Calculations on 3-Methylisoxazolo- and 2-Methyloxazolopyridines. J. Am. Soc. Mass Spectrom. 1995, 6, 962-971.

14. Giorgi, G.; Anzini, M.; Cappelli, A.; Corelli, F.; Vomero, S. Characterization and Differentiation of Heterocyclic Isomers. Part 2. Mass Spectrometry and Molecular Orbital Calculations on Pyrrolo [1,2-a][1,4] benzodiazepin-4-one, -6-one, -4,6-dione. J. Am. Soc. Mass Spectrom. 1996, 7, 653-663.

15. Giorgi, G.; Salvini, L.; Ponticelli, F.; Tedeschi, P. Characterization and Differentiation of Heterocyclic Isomers. Part 3. Study of High Internal Energy Ions Produced by Electron Ionization Mass Spectrometry on Methyl-1,2- and Methyl-1,3-Thiazolopyridines. J. Heterocyclic Chem. 1996, 33, 1895-1902.

16. Giorgi, G. Characterization and Differentiation of Heterocyclic Isomers. Part 5. About Mass Spectra and Library Entries of Benz(is)oxazoles. J. Mass Spectrom. 1998, 33, 1033-1036.

17. Donati, D.; Fusi, S.; Ponticelli, F.; Roncucci, G. Photochemical $\alpha$-Cyanoethylation of Indoles. Gazz. Chim. Ital. 1994, 124, 71-76.

18. Plaziak, A. S.; Celewicz, L. Mass Spectrometry of 5-(3-Alkyl$1 H$-indol-2-yl)uracils. Org. Mass Spectrom. 1989, 24, 953-955.

19. Beynon, J. H. Mass Spectroscopy and its Applications to Organic Chemistry. Elsevier: Amsterdam, 1960; pp 397-403. 